\title{
Is CRT pro-arrhythmic? A comparative analysis of the occurrence of ventricular arrhythmias between patients implanted with CRTs and ICDs
}

\section{A. B. Gopalamurugan ${ }^{\dagger}$, G. Ganesha Babu ${ }^{\dagger}$, Dominic P. Rogers, Adam L. Simpson, Syed Y. Ahsan, Pier D. Lambiase, Anthony W. Chow, Martin D. Lowe, Edward Rowland and Oliver R. Segal*}

Department of Cardiac Electrophysiology, The Heart Hospital, Institute of Cardiovascular Sciences, University College London, UK

Edited by:

Gaetano Santulli, Columbia, USA

Reviewed by:

Eleonora Savio Galimberti,

Vanderbilt University, USA

Antonio Anastasio, University of

Salerno, Italy

\section{*Correspondence:}

Oliver R. Segal, Department of

Electrophysiology, The Heart

Hospital, 16-18 Westmoreland

Street, London, W1G 8PH, UK

e-mail: oliver.segal@uclh.nhs.uk

these authors have contributed equally to this work.

\begin{abstract}
Aim and Hypothesis: Despite the proven symptomatic and mortality benefit of cardiac resynchronization therapy (CRT), there is anecdotal evidence it may be pro-arrhythmic in some patients. We aimed to identify if there were significant differences in the incidence of ventricular arrhythmias (VAs) in patients undergoing CRT-D and implantable cardioverter-defibrillators (ICD) implantation for primary prevention indication. We hypothesized that CRT is unlikely to be pro-arrhythmic based on the positive mortality and morbidity data from large randomized trials.
\end{abstract}

Methods and Results: A retrospective analysis of device therapies for VA in a primary prevention device cohort was performed. Patients with ischemic (IHD) and non-ischemic (DCM) cardiomyopathy and ICD or CRT+ICD devices (CRT-D) implanted between 2005 and 2007 without prior history of sustained VA were included for analysis. VA episodes were identified from stored electrograms and defined as sustained (VTNF) if therapy [anti-tachycardia pacing (ATP) or shocks] was delivered or non-sustained (NSVT) if not. Of a total of 180 patients, 117 (68\% male) were in the CRT-D group, 42\% IHD, ejection fraction (EF) $24.5 \pm 8.2 \%$ and mean follow-up $23.9 \pm 9.8$ months. 63 patients (84\% male) were in the ICD group, 60\% IHD, EF $27.7 \pm 7.2 \%$ and mean follow-up $24.6 \pm$ 10.8 months. Overall, there was no significant difference in the incidence of VA $(35.0$ vs. $38.1 \%, p=0.74)$, sustained VT (21.3 vs. $28.5 \%, p=0.36)$ or NSVT $(12.8$ vs. $9.5 \%$, $p=0.63$ ) and no significant difference in type of therapy received for VTNF: ATP (68 vs. $66.6 \%, p=0.73$ ) and shocks (32 vs. $33.3 \%, p=0.71$ ) between the CRT-D and ICD groups, respectively.

Conclusion: In patients with cardiomyopathy receiving CRT-D and ICDs for primary prophylaxis, there was no significant difference in the incidence of VA. From this single center retrospective analysis, there is no evidence to support cardiac resynchronization causing pro-arrhythmia.

Keywords: cardiac resynchronization therapy, ICD, heart failure, ventricular arrhythmia

\section{INTRODUCTION}

Cardiac resynchronization therapy (CRT) is an established treatment for chronic heart failure with proven mortality and morbidity benefits (Abraham et al., 2002; Cohen and Klein, 2002; John Sutton et al., 2003). In patients with heart failure and left bundle branch block on surface ECG, CRT reduces symptoms, hospitalization and sudden death (Cazeau et al., 2001; Abraham et al., 2002; Higgins et al., 2003). Patients with congestive heart failure are at increased risk of developing both monomorphic ventricular tachycardia (VT) (Figure 1) and ventricular fibrillation (VF) (Stevenson and Stevenson, 2001). Re-entry within the left ventricle (LV) is responsible for the majority of VT circuits (Stevenson and Delacretaz, 2000). In selected patients, implantable cardioverter defibrillator (ICD) implantation, singly or in combination with CRT (CRT-D), is indicated for primary or secondary prevention purposes, with proven mortality benefit and reduced risk of arrhythmic death for both device type (Walker et al., 2000; Zagrodzky et al., 2001; Martinelli et al., 2002; Higgins et al., 2003; Bristow et al., 2004; Cleland et al., 2005; Voigt et al., 2006). Based on the available data we hypothesized that CRT is unlikely to be pro-arrhythmic. However, there have also been numerous reports of pro-arrhythmia in patients treated with CRT, questioning its safety (Medina-Ravell et al., 2003; Di Cori et al., 2005; Fish et al., 2005; Shukla et al., 2005; Germano et al., 2006; Spragg and Kass, 2006). Various mechanisms for this phenomenon have been postulated, including reversal of the normal transmural sequence of activation, QT prolongation and increasing transmural dispersion of repolarization but much of these data are derived from in-vitro studies (Fish et al., 2005) and there has been a lack of clinical studies designed to investigate this problem in more 


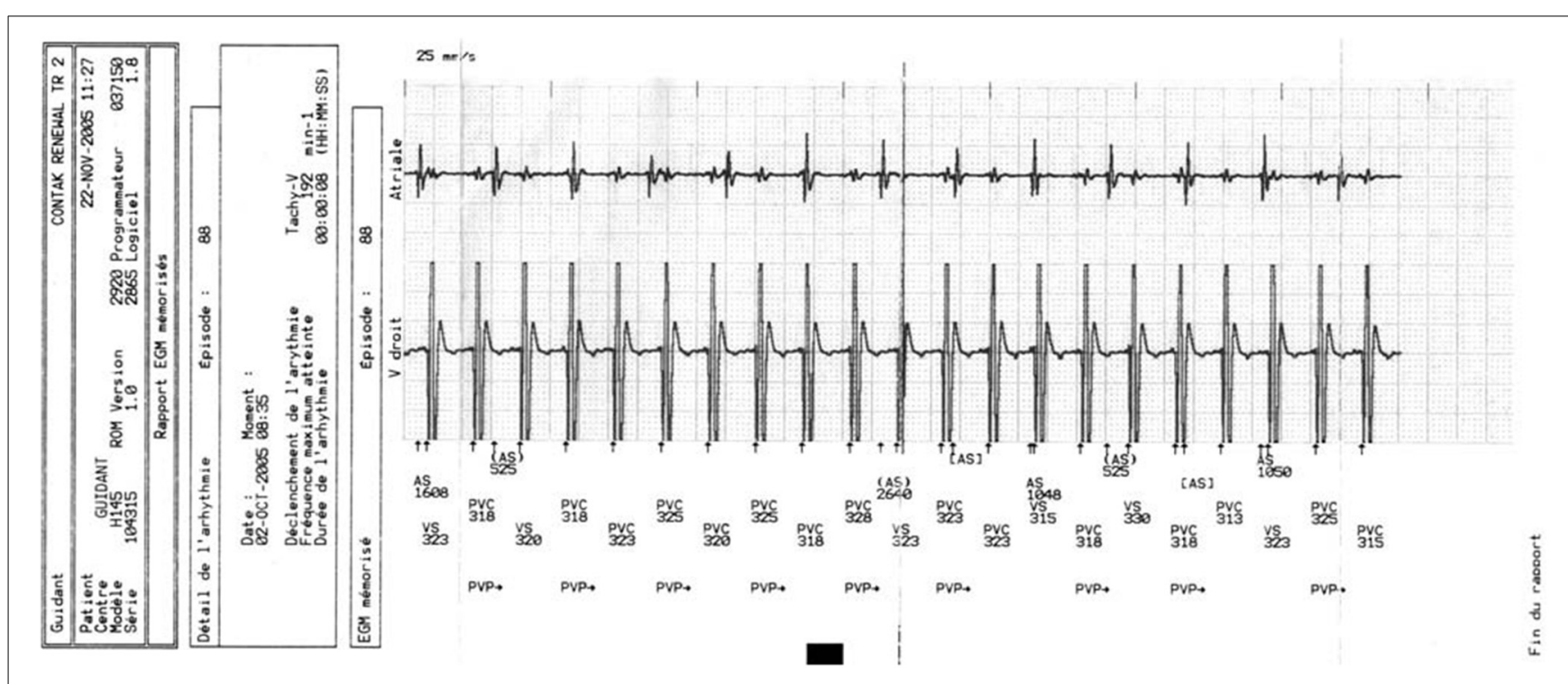

FIGURE 1 | A device interrogation printout showing ventricular tachycardia.

detail. Given the conflicting evidence for the pro-arrhythmic effects of CRT and the lack of clinical data, the aim of the present study was to investigate and compare the incidence of ventricular arrhythmias (VAs) in patients with either CRT/CRT-D or ICD devices indicated for primary prevention implanted in our center.

\section{METHODS}

This study is a single center retrospective analysis of patients with ICD and CRT/CRT-D devices implanted between January 2005 and December 2007. All patients had ischemic or nonischemic cardiomyopathy (idiopathic dilated cardiomyopathy) and poor left ventricular function. Patients with hypertrophic cardiomyopathy, infiltrative cardiomyopathy, ion-channelopathies, and congenital heart disease were excluded from the study. A total of 840 patients' device implantation records and indications were analyzed. Patients with devices implanted for secondary prevention of VA and those with a separate bradycardia pacing indication were excluded. Patients with normal left ventricular ejection fraction (EF) were excluded from the study. Demographic and clinical data, including renal function, were identified from patient records. Baseline renal function was classified using the estimated glomerular filtration rate (eGFR) by Modification of Diet in Renal Disease (MDRD) formula (Levey et al., 1999). Patients with eGFR $<60 \mathrm{mls} / \mathrm{min} / 1.73 \mathrm{~m}^{2}$ were classified as having chronic kidney disease (CKD) stage 3 or worse (National Kidney Foundation, 2002).

The cohort was divided into an ICD group and a CRT-D group. After exclusions, a total of 180 patients' device records were included. Details of episodes of VAs were obtained from patient notes, device clinic records and analysis of stored electrograms, downloaded device data from the previous 2.5 years, if available, in all patients.

\section{DEFINITIONS}

Device therapy was classified into either anti-tachycardia pacing (ATP) or shocks. Patients who received a combination of ATP and shocks for a single arrhythmia episode were classified in the "shock" category. VAs were defined as a VT or VF episode meeting device detection criteria, which then led to therapy delivery. Non-sustained ventricular tachycardia (NSVT) was defined as a VA episode detected by the device without therapy delivery due to spontaneous termination. Therapies delivered due to atrial fibrillation (AF) or supraventricular tachycardia were deemed inappropriate and were not included for analysis.

Patients had devices from the following manufacturers: Medtronic, Boston Scientific, St Jude and Biotronik. Criteria for detection of VAs were programmed to nominal settings at implant and were altered only at their physician's discretion. This also applied to therapy programming.

\section{STATISTICS}

Categorical variables are presented as percentages and continuous variables as mean $\pm \mathrm{SD}$ and/or median (interquartile range) where appropriate. Categorical variables were compared by the $X^{2}$-test or Fisher's exact test where applicable. Kaplan-Meier analysis was performed for survival probability and log rank test was used for time to event comparison. A $P$-value $<0.05$ was considered significant. Statistical comparisons were done using statistical software SPSS 15 (Manufacturer name, city, USA).

\section{RESULTS}

\section{PATIENT CHARACTERISTICS}

Between 2005 and 2007, 63 patients in the ICD group and 117 patients in the CRT-D group were identified after exclusion criteria. Mean follow-up was $24.6 \pm 10.8$ months in the ICD group and $23.9 \pm 9.8$ in the CRT-D group. Baseline patient characteristics are shown in Table $\mathbf{1 .}$

Patients in the CRT-D group had standard indications, including LVEF $\leq 35 \%$, NYHA class III-IV symptoms and QRS duration $>150 \mathrm{~ms}$ or QRS $>120 \mathrm{~ms}$ and echocardiographic evidence of dyssynchrony. All patients were on the maximum tolerated heart failure therapy. Of the 117 patients in the CRT-D group, 
Table 1 | Patient characteristics of both groups (ACE, Angiotension Converting Enzyme; ARB, Angiotensin Receptor Blockers; CKD, Chronic Kidney Disease; NYHA, New York Heart Association).

\begin{tabular}{lccc}
\hline $\begin{array}{l}\text { Patient } \\
\text { characteristics }\end{array}$ & $\begin{array}{c}\text { CRT-D group } \\
(\boldsymbol{n}=\mathbf{1 1 7})\end{array}$ & $\begin{array}{c}\text { ICD group } \\
(\boldsymbol{n}=\mathbf{6 3})\end{array}$ & Significance \\
\hline Age & $66 \pm 11$ & $65.3 \pm 13$ & $>0.05$ \\
Gender & & & \\
$\quad$ Male & $80(68 \%)$ & $53(84 \%)$ & 0.02 \\
$\quad$ Female & $37(32 \%)$ & $10(16 \%)$ & \\
Etiology & & & \\
$\quad$ Ischemic cardiomyopathy & $49(42 \%)$ & $38(60 \%)$ & 0.03 \\
$\quad$ Non-ischemic ardiomyopathy & $68(58 \%)$ & $25(40 \%)$ & $>0.05$ \\
Ejection fraction (\%) & $24.5 \pm 8.2$ & $27.7 \pm 7.2$ & $>0.05$ \\
Follow-up (months) & $23.9 \pm 9.8$ & $24.6 \pm 10.8$ & $>0.05$ \\
NYHA class (median) & III & II & 0.0003 \\
ACE inhibitors or ARBs & $97 \%$ & $92 \%$ & $>0.05$ \\
Amiodarone & $14 \%$ & $25 \%$ & $>0.05$ \\
Beta blockers & $86 \%$ & $69 \%$ & 0.026 \\
CKD stage 3 or above & $46 \%$ & $36 \%$ & $>0.05$ \\
\hline
\end{tabular}

$80(68 \%)$ were male, mean age $66 \pm 11$ years and of the 63 patients in the ICD group $53(84 \%)$ were male, with a mean age of $65.3 \pm 13$ years. The etiology of the underlying LV dysfunction in the CRT-D group was ischemic in 49 (42\%) patients and non-ischemic cardiomyopathy in $68(58 \%)$ patients. In the ICD group, $38(60 \%)$ patients had ischemic cardiomyopathy. Mean LV EF was $24.5 \pm 8.2 \%$ in the CRT-D group and $27.7 \pm 7.2 \%$ in the ICD group. Mean follow-up was $23.9 \pm 9.8$ months and $24.6 \pm 10.8$ months in the CRT-D and ICD groups, respectively. The median NYHA class of patients in the CRT-D group was 3 and was class 2 in the ICD group. 97\% of patients were established on an ACE inhibitor or Angiotensin receptor blocker in the CRT-D group and $92 \%$ in the ICD group. $14 \%$ in the CRT$\mathrm{D}$ group were on Amiodarone and $25 \%$ in the ICD group. In the CRT-D group $86 \%$ were on a beta-blocker and $69 \%$ in the ICD group. Analysis of patients' renal function revealed $46 \%$ of patients had CKD stage 3 or above in the CRT-D group and $36 \%$ of patients in the ICD group. Both groups were well matched for age, etiology, EF, follow up duration, ACE inhibitor/ARB use and the presence of CKD Stage 3 or more (all $p=$ NS) (see Table 1). Disparity was seen between the groups for NYHA class (worse in CRT-D group), gender (more females CRT-D group), number of patients with ischemic cardiomyopathy (less ischemic cardiomyopathy in CRT-D group) and beta-blocker usage (higher use in CRT-D group).

\section{INCIDENCE OF VENTRICULAR ARRHYTHMIAS}

In the CRT-D group, 35\% of patients (41/117) exhibited VAs, and of these, $25(60.9 \%)$ were VT and $16(39.02 \%)$ were NSVT. Among those patients with VT, 17 (68\%) were treated with ATP and $6(24 \%)$ with shocks, $2(8 \%)$ were treated with ATP followed by a shock. In the ICD group 24/63 (38.1\%) patients had VAs, of which18 (75\%) were VT and $6(25 \%)$ were NSVT. Among the patients who had VT, $12(66.6 \%)$ were treated with ATP and $6(33.3 \%)$ with shocks. There was no significant difference

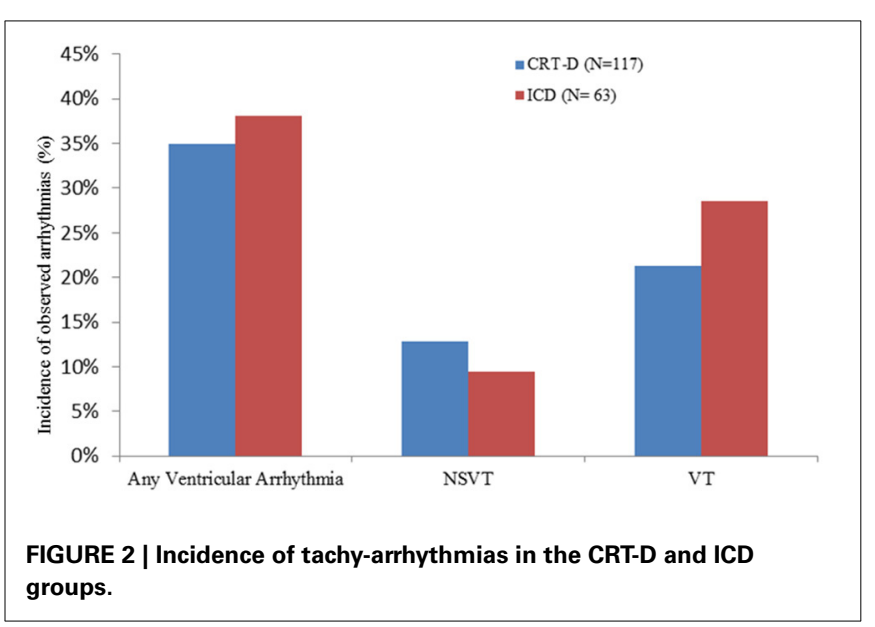

in the incidence of VAs between the CRT-D and ICD groups $(p=0.74)$. There were no significant differences in the incidence of VT $(p=0.36)$ and NSVT $(p=0.63)$, nor was there a significant difference in the number of patients who received ATP or shocks $(p=0.714)$ in either groups (Figure 2).

Using a Kaplan-Meier survival analysis, no significant difference in event free survival probability between the two groups were identified for freedom from VA, VT/VF or NSVT (Figures 3-5).

A Cox regression analysis was performed using Backward stepwise Ward rule for the occurrence of VT/VF with covariatesAge, Sex, type of intervention (ICD or CRT-D), Use of Amiodarone, Beta blocker, ACE inhibitor, NYHA Class and mean $\mathrm{EF}$ at the time of device implant and CKD. This showed that Male Sex $(p=0.001)$, presence of CKD $($ eGFR $<60)(p=0.01)$ and Age $(p=0.012)$ to be significant predictors for Time to VT/VF.

\section{SUB-GROUP ANALYSIS BASED ON ETIOLOGY}

A further sub-group analysis was performed according to etiology of left ventricular dysfunction.

\section{Ischemic cardiomyopathy sub-group}

Baseline characteristics were similar between both groups (Table 2), except NYHA class $(p=0.0003)$ and numbers of patients on Amiodarone $(p=0.02)$ or Beta-blockers $(p=0.03)$. VAs occurred in $21 / 49(42 \%)$ in the CRT-D group vs. $16 / 38(42 \%)$ in the ICD group $(p=0.94)$. VT/VF occurred in $14 / 49(28.5 \%)$ patients in the CRT-D group vs. $11 / 38(28.9 \%)$ in the ICD group $(p=0.96)$ (Figure 6).

\section{Non-ischemic cardiomyopathy sub-group}

There were more males in the ICD group (88\%) than the CRTD group $(55 \%)(p=0.002)$ (Table 3). VAs occurred in $20 / 68$ (29\%) patients in the CRT-D group vs. $9 / 26(35 \%)$ in the ICD group $(p=0.62)$. Sustained VA (VT/VF) occurred in $11 / 68$ $(16 \%)$ patients in the CRT-D group vs. $8 / 26(31 \%)$ in the ICD group $(p=0.15)$, implying a trend toward a higher incidence of sustained VA in patients with ICDs although statistically not significant (Figure 7). 


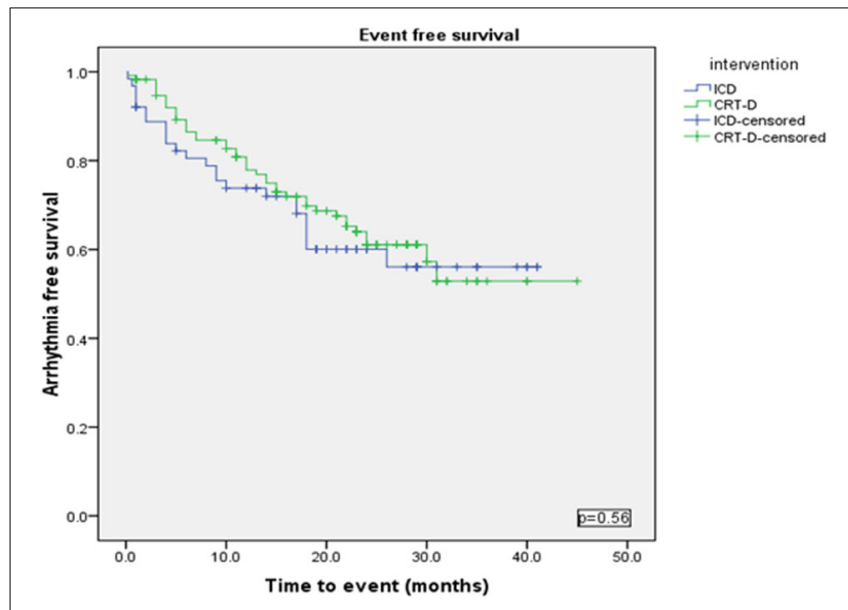

FIGURE 3 | Kaplan Meyer survival analysis of the occurrence of ventricular tachyarrhythmia between ICD and CRT-D group.

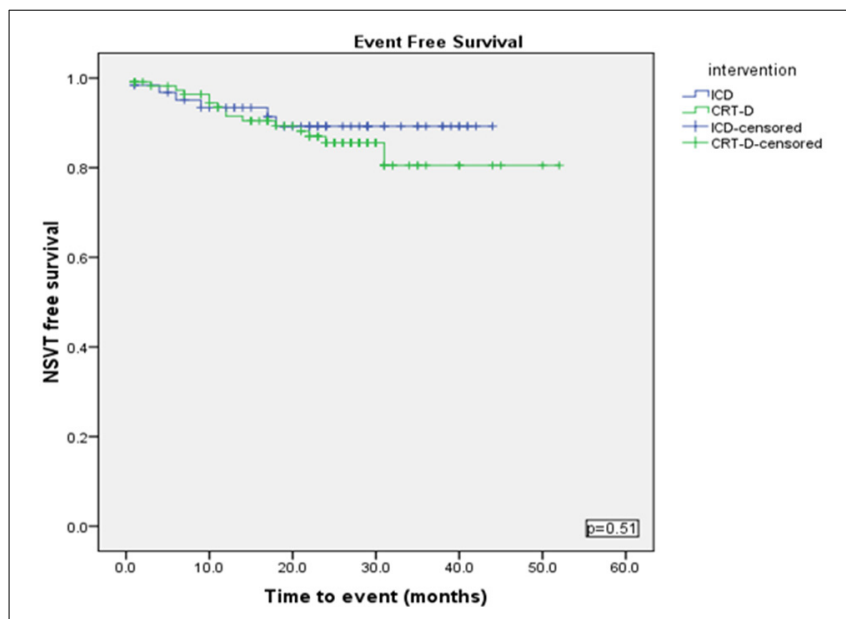

FIGURE 4 | Kaplan Meyer survival analysis of the occurrence of NSVT between ICD and CRT-D groups.

After stratifying into Ischemic and Non Ischemic Cardiomyopathy, a Cox regression analysis was performed using Backward stepwise Ward rule for the occurrence of VT/VF with covariates-Age, Sex, type of intervention (ICD or CRT-D), Use of Amiodarone, Beta blocker, ACE inhibitor, NYHA Class and mean $\mathrm{EF}$ at the time of device implant and presence of CKD.

Age $(p=0.08)$ and Male sex $(p=0.027)$ were found to be independent predictor for time to VT/VF in Ischemic Cardiomyopathy group. In the NICM group, Age $(p=0.01)$, Sex $(p=0.04)$, Presence of CKD $(p=0.01)$ and Intervention typeICD $(p=0.03)$ were independent predictors of time to VT/VF occurrence.

\section{DISCUSSION}

The principal finding of the present study was the observation of no difference in burden of VA in patients implanted with ICDs or CRT-Ds for primary prevention purposes, in a reasonably

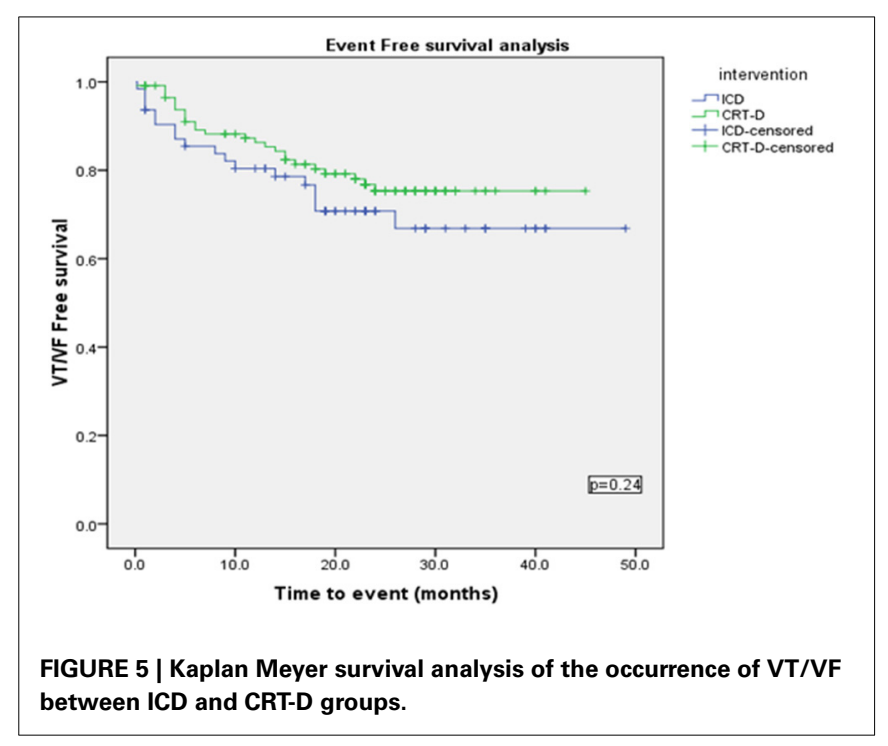

well matched cohort. To our knowledge, this is the first retrospective study designed to specifically examine the difference in incidence of any VAs between these patient groups. In addition, there were no significant difference in the occurrence of sustained VA in the two groups $(21.3 \%$ in CRT-D group vs. $28.5 \%$ in ICD group, $p=0.36$ ). Sub-group analysis showed similar reductions in VAs in different etiologies of underlying cardiomyopathy. These results are supported by data from the COMPANION trial (Comparison of Medical Therapy, Pacing, and Defibrillation in Chronic Heart Failure study) (Bristow et al., 2004), which showed a significant reduction in all cause mortality and hospitalizations in patients receiving CRT or CRT-D devices compared to optimal medical therapy alone. The latter is important as one would assume an increase in sustained VAs would have led to ICD therapies resulting in increased hospitalizations in these patients. This is corroborated by data from the Cardiac Resynchronization in Heart Failure study (CARE-HF) of patients receiving CRT compared to medical therapy (Cleland et al., 2005), which showed a $37 \%$ reduction in all cause mortality and hospitalizations, but also significant improvement in patients' quality of life at 90 day follow-up. This too implies a reduction in ventricular tachyarrhythmia burden.

\section{MECHANISMS BY WHICH CRT MAY BE PRO- OR ANTI-ARRHYTHMIC}

It is well known that CRT may cause reverse mechanical and electrical remodeling of the LV (Saxon et al., 2002; Auricchio and Abraham, 2004; Leclercq and Hare, 2004). At a sub-cellular level, the favorable role of CRT in re-organization of sub-cellular structure and protein distribution associated with excitation contraction (EC) coupling has been shown by Sachse et al. (2012) The role of sub-cellular structure transverse tubular system $(t-$ system) along with spatial orientation of Ryanodine receptor clusters is an important requisite in EC coupling, which is invariably altered in dyssynchronous heart failure (Louch et al., 2010). CRT has been shown to restore structure and functional restitution of the t-system as early as 3 weeks in canine model (Sachse et al., 2012). The role of miRNA down regulation in heart failure 
Table 2 | Ischemic cardiomyopathy-Patient characteristics.

\begin{tabular}{lccc}
\hline $\begin{array}{l}\text { Patient } \\
\text { characteristics }\end{array}$ & $\begin{array}{c}\text { CRT-D group } \\
(\boldsymbol{n}=\mathbf{4 9 )}\end{array}$ & $\begin{array}{c}\text { ICD group } \\
(\boldsymbol{n}=\mathbf{3 8})\end{array}$ & Significance \\
\hline Age & $67.5 \pm 9$ & $71.4 \pm 9$ & 0.60 \\
Gender & & & \\
$\quad$ Male & $42(85 \%)$ & $31(81 \%)$ & 0.77 \\
Ejection fraction (\%) & $26.08 \pm 7.7$ & $27.0 \pm 6.3$ & 0.56 \\
Follow-up (months) & $24.24 \pm 10.4$ & $24.79 \pm 11.1$ & 0.81 \\
NYHA class (median) & III & II & 0.0003 \\
ACE inhibitors or ARBs & $96 \%(36)$ & $95 \%(30)$ & 0.96 \\
Amiodarone & $13 \%(5)$ & $37 \%(12)$ & 0.02 \\
Beta blockers & $60 \%(23)$ & $84 \%(27)$ & 0.03 \\
CKD stage 3 or more & $59 \%(29)$ & $46 \%(17)$ & 0.27
\end{tabular}

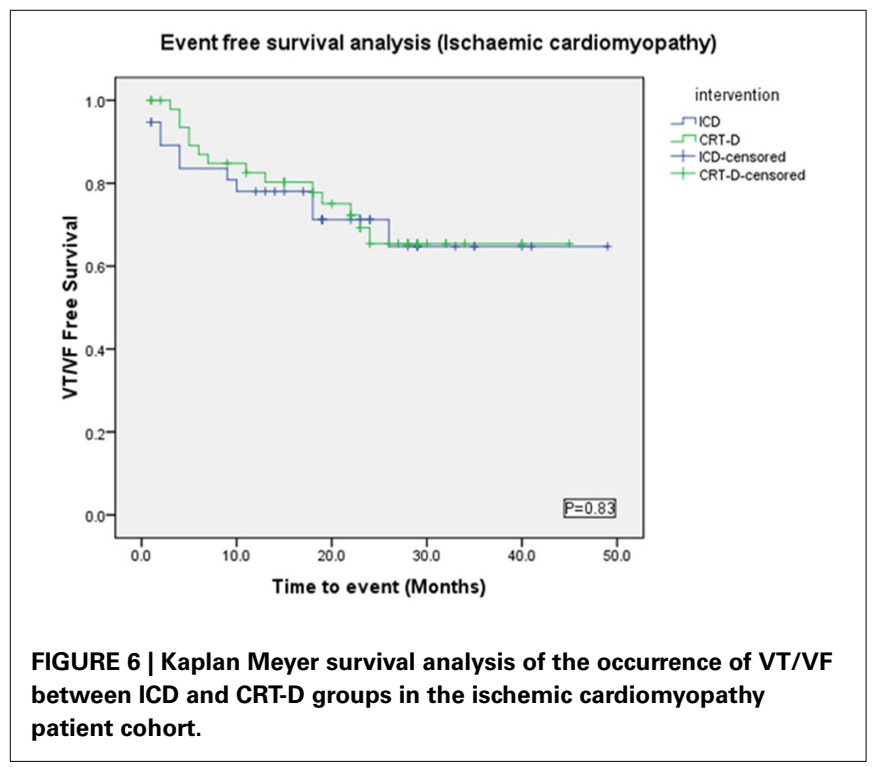

Table 3 | Non-ischemic cardiomyopathy-Patient characteristics.

\begin{tabular}{lccc}
\hline $\begin{array}{l}\text { Patient } \\
\text { characteristics }\end{array}$ & $\begin{array}{c}\text { CRT-D group } \\
(\boldsymbol{n}=\mathbf{6 8})\end{array}$ & $\begin{array}{c}\text { ICD group } \\
(\boldsymbol{n}=\mathbf{2 6})\end{array}$ & Significance \\
\hline Age & $63.6 \pm 13$ & $61.3 \pm 14$ & 0.46 \\
Gender & & & \\
$\quad$ Male & $55 \%(38)$ & $88 \%(23)$ & 0.002 \\
Ejection fraction (\%) & $23.4 \pm 8.5$ & $28.6 \pm 9.0$ & 0.011 \\
Follow-up (months) & $23.7 \pm 9.5$ & $23.8 \pm 10.7$ & 0.9 \\
NYHA class (median) & III & $\|$ & 0.0003 \\
ACE inhibitors or ARBs & $75 \%(51)$ & $80 \%(21)$ & 0.18 \\
Amiodarone & $12 \%(8)$ & $4 \%(1)$ & 0.43 \\
Beta blockers & $75 \%(41)$ & $90 \%(19)$ & 0.2 \\
CKD stage 3 or more & $36 \%(25)$ & $23 \%(6)$ & 0.22 \\
\hline
\end{tabular}

patients and CRT and miRNA response to CRT in both responders and non-responders to CRT have been recently shown by Sardu et al. focusing on the miR-mediated modulation of cardiac angiogenesis, apoptosis, fibrosis and membrane ionic currents (Sardu et al., 2014). Possible mechanisms for reduction in VA with CRT include a decrease in local conduction delay, decreased pause

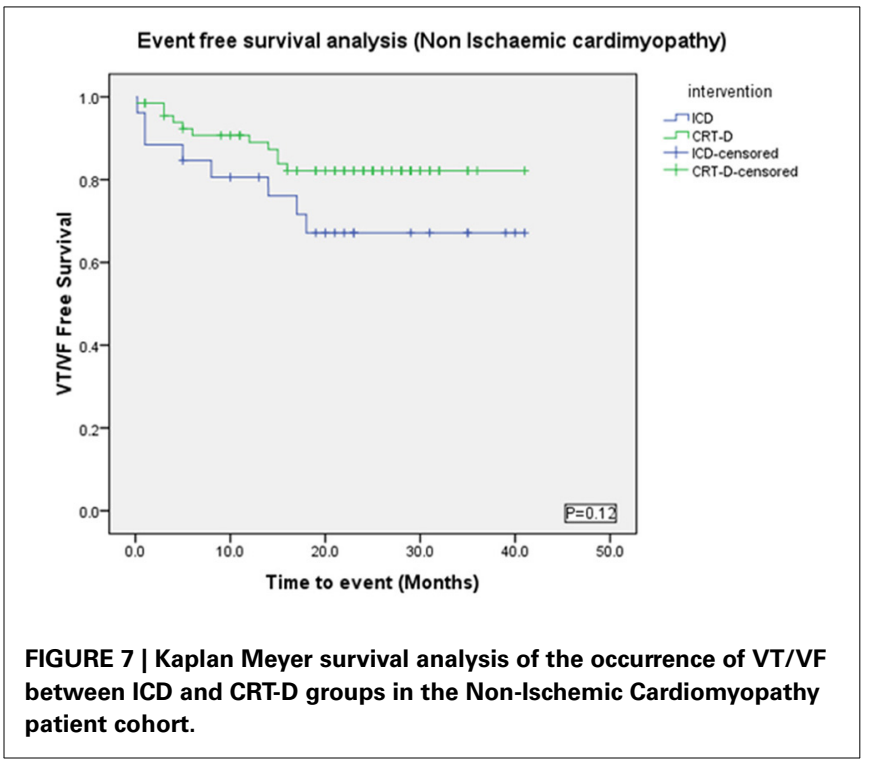

dependant ectopic firing and decreased circulating catecholamine levels through hemodynamic effects (Zagrodzky et al., 2001). Over time, electrical and mechanical remodeling of the ventricles might exert anti-arrhythmic effects. In the MADIT-CRT trial, "super-responders" to CRT-D (with reductions of $>25 \%$ in left ventricular end-systolic volume) had significantly lower VA compared to non-responders and ICD-only patients (Barsheshet et al., 2011). CRT is also associated with favorable reverse remodeling effects on the left atrium (LA), in addition to its well-established effects on the LV, thereby possibly reducing the risk for the development of Atrial tachycardia (AT) and AF in patients with HF (Kies et al., 2006; Fung et al., 2008). In CRT responders, significant improvement in left atrial (LA) functional, structural and anatomic remodeling have been shown in detailed echocardiographic assessments during follow-up (Donal et al., 2009). In addition, CRT responders have been shown to develop much lower incidence of AF during follow up period compared to non-responders (D'Ascia et al., 2011). In the MADIT-CRT trial, favorable reverse remodeling of the LA with CRT-D therapy was associated with a significant reduction in risk of subsequent AT (Brenyo et al., 2011). Although aforementioned studies and few other small studies mostly observational have reported decreased atrial arrhythmic incidence in CRT patients, a post-hoc analysis of large randomized CARE-HF study failed to show any atrial antiarrhythmic effect of CRT (Hoppe et al., 2006). These studies have been evaluated in a recent meta-analysis by Hess et al. (2013)

The effects of CRT may also potentially be pro-arrhythmic. Pacing the LV epicardially results in non-physiological direction of activation which can lead to prolongation of action potential duration, potentially leading to prolongation of repolarization (Medina-Ravell et al., 2003; Fish et al., 2005). In patients with diseased ventricles with heterogeneous conduction, re-entry may be facilitated by pacing close to scar border or lines of block or may provoke ectopy leading to arrhythmia (Fish et al., 2005).

How the balance of these potential pro- and anti-arrhythmic mechanisms lies in different groups of patients, different etiologies of heart disease, and different conduction defects is 
unknown. Data from the present study and previous large, randomized trials (Voigt et al., 2006; Barsheshet et al., 2011) would support a net beneficial effect overall, but whether this is true for each individual patient is also undetermined. Previous reports of VT storm occurring acutely after CRT implantation demonstrate this balance can be difficult to predict (Kantharia et al., 2006; Nayak et al., 2008) and may simply reflect the lack of time for reverse remodeling to occur with CRT in some individuals. One can speculate that as this is only seen in a small fraction of patients, unusual interplay of specific characteristics may be responsible. LV structural abnormalities, local conduction delay and repolarization abnormalities, LV lead position and pacing site, circulating catecholamine levels as a result of hemodynamic status, medications and ion channel function may all be culprits. Finally, patients with indications for CRT are, by the nature of their disease process, prone to VA and CRT may not always be responsible for an increase in arrhythmia burden.

\section{DIFFERENCES IN CRT AND ICD POPULATIONS}

Patients with devices implanted for secondary prevention, ion channelopathy, HCM, and congenital heart disease were excluded to facilitate comparison between the two etiologies of heart failure most commonly leading to device implantation. Overall, the two groups were reasonably well matched. However, there were differences between these groups, which requires further discussion. NYHA class was significantly higher in the CRT-D group. This is not unexpected given the criteria for CRT implantation in the UK stipulates NYHA class III-IV symptoms (ref NICE guidelines) (Appraisal Committee members and NICE project team, 2007), whereas heart failure symptoms need not be severe for ICD implantation. As a consequence, one might expect more severe underlying heart dysfunction in the CRT cohort, putting them more at risk of arrhythmia, but this is not borne out by the echocardiographic data from these two groups in the present study (including LV systolic function), which showed no significant difference in the mean EF, including the sub-group analysis. We therefore speculate this symptomatic difference between the groups is unlikely to influence the results of the study.

Patients in the ICD arm had a higher proportion of males and patients with an ischemic substrate. The two cohorts in the analysis were well matched in respect to renal function. This is important as renal disease is a well-recognized independent risk factor for sudden death in heart failure patients (Korantzopoulos et al., 2009; Kreuz et al., 2010; Shamseddin and Parfrey, 2011) and often co-exists in patients with impaired LV function. Electrolyte abnormalities as a result of renal disease may also predispose to VA (Whitman et al., 2012) and therefore act as a confounding factor. The Cox regression analysis in our study identified presence of CKD as one of the independent predictors of VT/VF. Advanced age and male-sex were the other independent predictors of sustained VAs. Additional comorbidities, including presence of coronary disease and CKD with advancing age might explain, age being independent predictor of sustained VA.

\section{LIMITATIONS}

This study is limited by its retrospective nature of data collection. Some baseline characteristics (gender and drugs) were not well matched between the two groups which may have acted as confounders. Moreover the sizes of the cohorts studied were small and this is well acknowledged as one of the limitations of this study. The use of device therapies (ATP or shocks) as a surrogate for sustained VA is likely to be highly sensitive, but not specific. Nominal settings for detection of VF on most devices is relatively short (for example 18 out 24 intervals on Medtronic devices or minimum $1 \mathrm{~s}$ of tachycardia on Boston Scientific devices) meaning that therapy is delivered very early after the onset of tachycardia, which may have terminated spontaneously shortly afterwards. Thus, using this measure is likely to overestimate the real proportion of sustained arrhythmia, but one would expect this to be similar between the two groups as long as programmed device detection criteria was also similar.

\section{AUTHOR CONTRIBUTIONS}

All authors contributed to manuscript concept/design, data analysis/interpretation, drafting article, critical revision of article, approval of article, statistics, and data collection.

\section{REFERENCES}

Abraham, W. T., Fisher, W. G., Smith, A. L., Delurgio, D. B., Leon, A. R., Loh, E., et al. (2002). Cardiac resynchronization in chronic heart failure. N. Engl. J. Med. 346, 1845-1853. doi: 10.1056/NEJMoa013168

Appraisal Committee members and NICE project team. (2007). TA-120 NICE Guidelines on Cardiac Resynchronisation Therapy. London: National Institue for Health and Care Excellence.

Auricchio, A., and Abraham, W. T. (2004). Cardiac resynchronization therapy: current state of the art: cost versus benefit. Circulation 109, 300-307. doi: 10.1161/01.CIR.0000115583.20268.E1

Barsheshet, A., Wang, P. J., Moss, A. J., Solomon, S. D., Al Ahmad, A., McNitt, S., et al. (2011). Reverse remodeling and the risk of ventricular tachyarrhythmias in the MADIT-CRT (Multicenter automatic defibrillator implantation trialcardiac resynchronization therapy). J. Am. Coll. Cardiol. 57, 2416-2423. doi: 10.1016/j.jacc.2010.12.041

Brenyo, A., Link, M. S., Barsheshet, A., Moss, A. J., Zareba, W., Wang, P. J., et al. (2011). Cardiac resynchronization therapy reduces left atrial volume and the risk of atrial tachyarrhythmias in MADIT-CRT (Multicenter automatic defibrillator implantation trial with cardiac resynchronization therapy). J. Am. Coll. Cardiol. 58, 1682-1689. doi: 10.1016/j.jacc.2011.07.020

Bristow, M. R., Saxon, L. A., Boehmer, J., Krueger, S., Kass, D. A., De Marco, T., et al. (2004). Cardiac-resynchronization therapy with or without an implantable defibrillator in advanced chronic heart failure. N. Engl. J. Med. 350, 2140-2150. doi: 10.1056/NEJMoa032423

Cazeau, S., Leclercq, C., Lavergne, T., Walker, S., Varma, C., Linde, C., et al. (2001). Effects of multisite biventricular pacing in patients with heart failure and intraventricular conduction delay. N. Engl. J. Med. 344, 873-880. doi: 10.1056/NEJM200103223441202

Cleland, J. G., Daubert, J. C., Erdmann, E., Freemantle, N., Gras, D., Kappenberger, L., et al. (2005). The effect of cardiac resynchronization on morbidity and mortality in heart failure. N. Engl. J. Med. 352, 1539-1549. doi: 10.1056/NEJMoa050496

Cohen, T. J., and Klein, J. (2002). Cardiac resynchronization therapy for treatment of chronic heart failure. J. Invasive Cardiol. 14, 48-53.

D’Ascia, S. L., D’Ascia, C., Marino, V., Lombardi, A., Santulli, R., Chiariello, M., et al. (2011). Cardiac resynchronisation therapy response predicts occurrence of atrial fibrillation in non-ischaemic dilated cardiomyopathy. Int. J. Clin. Pract. 65, 1149-1155. doi: 10.1111/j.1742-1241.2011.02732.x

Di Cori, A., Bongiorni, M. G., Arena, G., Soldati, E., Giannola, G., Zucchelli, G., et al. (2005). New-onset ventricular tachycardia after cardiac resynchronization therapy. J. Interv. Card. Electrophysiol. 12, 231-235. doi: 10.1007/s10840-0056555-1

Donal, E., Tan, K., Leclercq, C., Ollivier, R., Derumeaux, G., Bernard, M., et al. (2009). Left atrial reverse remodeling and cardiac resynchronization therapy 
for chronic heart failure patients in sinus rhythm. J. Am. Soc. Echocardiogr. 22, 1152-1158. doi: 10.1016/j.echo.2009.06.005

Fish, J. M., Brugada, J., and Antzelevitch, C. (2005). Potential proarrhythmic effects of biventricular pacing. J. Am. Coll. Cardiol. 46, 2340-2347. doi: 10.1016/j.jacc.2005.08.035

Fung, J. W., Yip, G. W., Zhang, Q., Fang, F., Chan, J. Y., Li, C. M., et al. (2008). Improvement of left atrial function is associated with lower incidence of atrial fibrillation and mortality after cardiac resynchronization therapy. Heart Rhythm. 5, 780-786. doi: 10.1016/j.hrthm.2008.02.043

Germano, J. J., Reynolds, M., Essebag, V., and Josephson, M. E. (2006). Frequency and causes of implantable cardioverter-defibrillator therapies: is device therapy proarrhythmic? Am. J. Cardiol. 97, 1255-1261. doi: 10.1016/j.amjcard.2005.11.048

Hess, P. L., Jackson, K. P., Hasselblad, V., and Al Khatib, S. M. (2013). Is cardiac resynchronization therapy an antiarrhythmic therapy for atrial fibrillation? A systematic review and meta-analysis. Curr. Cardiol. Rep. 15, 330. doi: 10.1007/s11886-012-0330-6

Higgins, S. L., Hummel, J. D., Niazi, I. K., Giudici, M. C., Worley, S. J., Saxon, L. A., et al. (2003). Cardiac resynchronization therapy for the treatment of heart failure in patients with intraventricular conduction delay and malignant ventricular tachyarrhythmias. J. Am. Coll. Cardiol. 42, 1454-1459. doi: 10.1016/S0735-1097(03)01042-8

Hoppe, U. C., Casares, J. M., Eiskjaer, H., Hagemann, A., Cleland, J. G., Freemantle, N., et al. (2006). Effect of cardiac resynchronization on the incidence of atrial fibrillation in patients with severe heart failure. Circulation 114, 18-25. doi: 10.1161/CIRCULATIONAHA.106.614560

John Sutton, M. G., Plappert, T., Abraham, W. T., Smith, A. L., DeLurgio, D. B., Leon, A. R., et al. (2003). Effect of cardiac resynchronization therapy on left ventricular size and function in chronic heart failure. Circulation 107, 1985-1990. doi: 10.1161/01.CIR.0000065226.24159.E9

Kantharia, B. K., Patel, J. A., Nagra, B. S., and Ledley, G. S. (2006) Electrical storm of monomorphic ventricular tachycardia after a cardiacresynchronization-therapy-defibrillator upgrade. Europace 8, 625-628. doi: 10.1093/europace/eul049

Kies, P., Leclercq, C., Bleeker, G. B., Crocq, C., Molhoek, S. G., Poulain, C., et al. (2006). Cardiac resynchronisation therapy in chronic atrial fibrillation: impact on left atrial size and reversal to sinus rhythm. Heart 92, 490-494. doi: 10.1136/hrt.2005.064816

Korantzopoulos, P., Liu, T., Li, L., Goudevenos, J. A., and Li, G. (2009). Implantable cardioverter defibrillator therapy in chronic kidney disease: a meta-analysis. Europace 11, 1469-1475. doi: 10.1093/europace/eup282

Kreuz, J., Balta, O., Linhart, M., Fimmers, R., Lickfett, L., Mellert, F., et al. (2010). An impaired renal function and advanced heart failure represent independent predictors of the incidence of malignant ventricular arrhythmias in patients with an implantable cardioverter/defibrillator for primary prevention. Europace 12, 1439-1445. doi: 10.1093/europace/euq283

Leclercq, C., and Hare, J. M. (2004). Ventricular resynchronization: current state of the art. Circulation 109, 296-299. doi: 10.1161/01.CIR.0000113458. 76455.03

Levey, A. S., Bosch, J. P., Lewis, J. B., Greene, T., Rogers, N., and Roth, D. (1999). A more accurate method to estimate glomerular filtration rate from serum creatinine: a new prediction equation. Modification of diet in renal disease study group. Ann. Intern. Med. 130, 461-470.

Louch, W. E., Sejersted, O. M., and Swift, F. (2010). There goes the neighborhood: pathological alterations in T-tubule morphology and consequences for cardiomyocyte $\mathrm{Ca}^{2+}$ handling. J. Biomed. Biotechnol. 2010:503906. doi: $10.1155 / 2010 / 503906$

Martinelli, F. M., Pedrosa, A. A., Costa, R., Nishioka, S. A., Siqueira, S. F., Tamaki, W. T., et al. (2002). Biventricular pacing improves clinical behavior and reduces prevalence of ventricular arrhythmia in patients with heart failure. Arq. Bras. Cardiol. 78, 110-113. doi: 10.1590/\$0066-782X20020001 00010

Medina-Ravell, V. A., Lankipalli, R. S., Yan, G. X., Antzelevitch, C., MedinaMalpica, N. A., Medina-Malpica, O. A., et al. (2003). Effect of epicardial or biventricular pacing to prolong QT interval and increase transmural dispersion of repolarization: does resynchronization therapy pose a risk for patients predisposed to long QT or torsade de pointes? Circulation 107, 740-746. doi: 10.1161/01.CIR.0000048126.07819.37
National Kidney Foundation. (2002). K/DOQI clinical practice guidelines for chronic kidney disease: evaluation, classification, and stratification. Am. J. Kidney Dis. 39(Suppl. 1), S1-S266.

Nayak, H. M., Verdino, R. J., Russo, A. M., Gerstenfeld, E. P., Hsia, H. H., Lin, D., et al. (2008). Ventricular tachycardia storm after initiation of biventricular pacing: incidence, clinical characteristics, management, and outcome. J. Cardiovasc. Electrophysiol. 19, 708-715. doi: 10.1111/j.1540-8167.2008.01122.x

Sachse, F. B., Torres, N. S., Savio-Galimberti, E., Aiba, T., Kass, D. A., Tomaselli, G. F., et al. (2012). Subcellular structures and function of myocytes impaired during heart failure are restored by cardiac resynchronization therapy. Circ. Res. 110, 588-597. doi: 10.1161/CIRCRESAHA.111.257428

Sardu, C., Marfella, R., Santulli, G., and Paolisso, G. (2014). Functional role of miRNA in cardiac resynchronization therapy. Pharmacogenomics 15 , 1159-1168. doi: 10.2217/pgs.14.76

Saxon, L. A., De Marco, T., Schafer, J., Chatterjee, K., Kumar, U. N., and Foster, E. (2002). Effects of long-term biventricular stimulation for resynchronization on echocardiographic measures of remodeling. Circulation 105, 1304-1310. doi: $10.1161 /$ hc1102.105730

Shamseddin, M. K., and Parfrey, P. S. (2011). Sudden cardiac death in chronic kidney disease: epidemiology and prevention. Nat. Rev. Nephrol. 7, 145-154. doi: 10.1038/nrneph.2010.191

Shukla, G., Chaudhry, G. M., Orlov, M., Hoffmeister, P., and Haffajee, C. (2005). Potential proarrhythmic effect of biventricular pacing: fact or myth? Heart Rhythm 2, 951-956. doi: 10.1016/j.hrthm.2005.05.019

Spragg, D. D., and Kass, D. A. (2006). Pathobiology of left ventricular dyssynchrony and resynchronization. Prog. Cardiovasc. Dis. 49, 26-41. doi: 10.1016/j.pcad.2006.05.001

Stevenson, W. G., and Delacretaz, E. (2000). Radiofrequency catheter ablation of ventricular tachycardia. Heart 84, 553-559. doi: 10.1136/heart.84.5.553

Stevenson, W. G., and Stevenson, L. W. (2001). Prevention of sudden death in heart failure. J. Cardiovasc. Electrophysiol. 12, 112-114. doi: 10.1046/j.15408167.2001.00112.x

Voigt, A., Barrington, W., Ngwu, O., Jain, S., and Saba, S. (2006). Biventricular pacing reduces ventricular arrhythmic burden and defibrillator therapies in patients with heart failure. Clin. Cardiol. 29, 74-77. doi: 10.1002/clc.4960 290208

Walker, S., Levy, T. M., Rex, S., Brant, S., Allen, J., Ilsley, C. J., et al. (2000). Usefulness of suppression of ventricular arrhythmia by biventricular pacing in severe congestive cardiac failure. Am. J. Cardiol. 86, 231-233. doi: 10.1016/S0002-9149(00)00865-1

Whitman, I. R., Feldman, H. I., and Deo, R. (2012). CKD and sudden cardiac death: epidemiology, mechanisms, and therapeutic approaches. J. Am. Soc. Nephrol. 23 , 1929-1939. doi: 10.1681/ASN.2012010037

Zagrodzky, J. D., Ramaswamy, K., Page, R. L., Joglar, J. A., Sheehan, C. J., Smith, M. L., et al. (2001). Biventricular pacing decreases the inducibility of ventricular tachycardia in patients with ischemic cardiomyopathy. Am. J. Cardiol. 87, 1208-1210. doi: 10.1016/S0002-9149(01)01498-9

Conflict of Interest Statement: The authors declare that the research was conducted in the absence of any commercial or financial relationships that could be construed as a potential conflict of interest.

Received: 22 December 2013; accepted: 14 August 2014; published online: 17 September 2014.

Citation: Gopalamurugan AB, Ganesha Babu G, Rogers DP, Simpson AL, Ahsan SY, Lambiase PD, Chow AW, Lowe MD, Rowland E and Segal OR (2014) Is CRT pro-arrhythmic? A comparative analysis of the occurrence of ventricular arrhythmias between patients implanted with CRTs and ICDs. Front. Physiol. 5:334. doi: 10.3389/ fphys.2014.00334

This article was submitted to Cardiac Electrophysiology, a section of the journal Frontiers in Physiology.

Copyright (C) 2014 Gopalamurugan, Ganesha Babu, Rogers, Simpson, Ahsan, Lambiase, Chow, Lowe, Rowland and Segal. This is an open-access article distributed under the terms of the Creative Commons Attribution License (CC BY). The use, distribution or reproduction in other forums is permitted, provided the original author $(s)$ or licensor are credited and that the original publication in this journal is cited, in accordance with accepted academic practice. No use, distribution or reproduction is permitted which does not comply with these terms. 